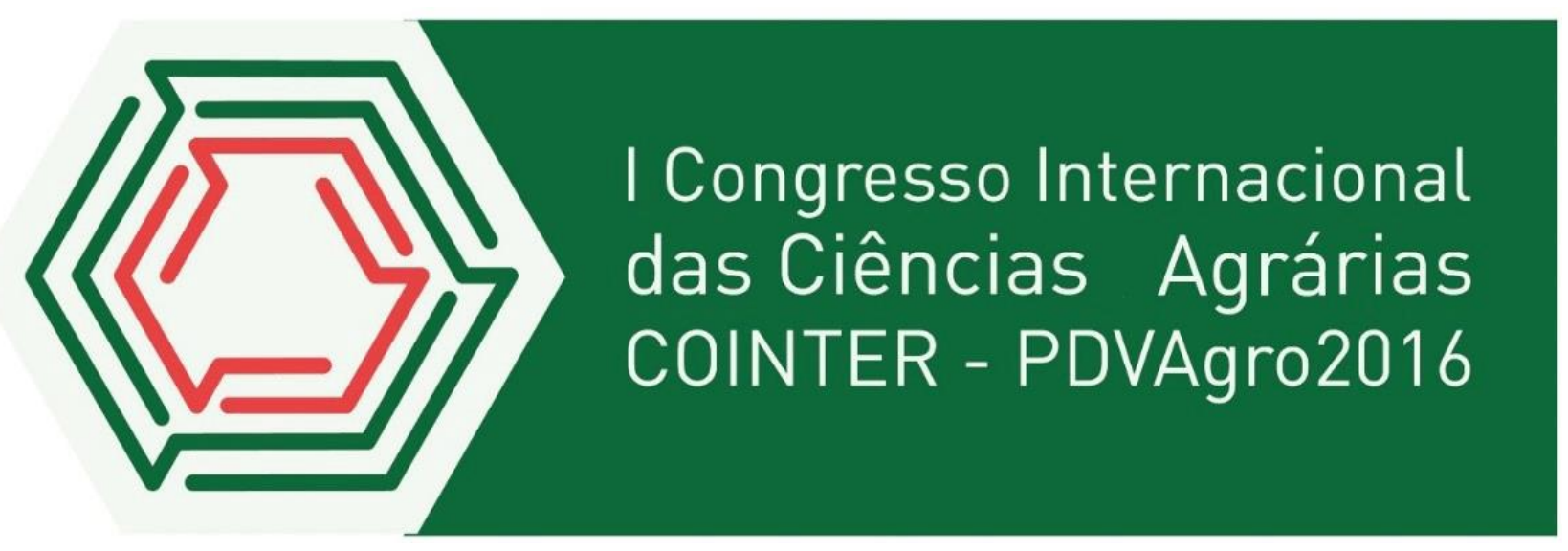

\title{
PRÁTICAS AGROECOLÓGICAS NO SEMIÁRIDO DE PERNAMBUCO
}

\author{
Apresentação: Relato de Experiência \\ Maciel Alves Tavares ${ }^{1}$; José Marques dos Santos $^{2}$; Bruno Wallace do Carmo Perônico ${ }^{3}$; \\ Erick Viana da Silva ${ }^{4}$
}

\section{Introdução}

As ciências agrárias abrangem diversas áreas de atuação, que proporcionam ao profissional uma série de oportunidades com inúmeros desafios, principalmente quando se trata de Agricultura Familiar.

Tendo em vista as dificuldades que os agricultores vêm enfrentando atualmente com o sistema de trabalho convencional, a Agroecologia surge como uma ciência que estabelece bases para a construção de estilos de agriculturas sustentáveis e de estratégias de desenvolvimento rural. (CAPORAL, 2004)

\section{Relato de Experiência}

O curso de Práticas Agroecológicas no Semiárido de Pernambuco nos proporcionou uma formação complementar acerca de práticas de base ecológica e sustentável voltadas para agricultura familiar. Durante o curso vivenciamos e participamos de práticas nas mais diversas áreas, tais como: Administração e Empreendedorismo, Irrigação, Fruticultura, Física e Biologia do Solo, Horticultura, Entomologia e Apicultura.

Durante o curso realizamos práticas no Centro de Vocações Tecnológicas de Agroecologia

\footnotetext{
${ }^{1}$ Bacharelado em Agronomia, Instituto Federal de Pernambuco Campus Vitória, macieltavares15@gmail.com

2 Bacharelado em Agronomia, Instituto Federal de Pernambuco Campus Vitória, josemarquesdossantos87@gmail.com

${ }^{3}$ Bacharelado em Agronomia, Instituto Federal de Pernambuco Campus Vitória, brunowperonico1@gmail.com

${ }^{4}$ Professor Mestre, Instituto Federal de Pernambuco Campus Vitória, erick.viana@vitoria.ifpe.edu.br
} 
(CVT), no Setor de Fruticultura do IF-Sertão Campus Petrolina Zona Rural, no Laboratório de Química e Física do Solo e na Ilha de Massangano.

No setor de horta do CVT realizamos práticas de colheita e pós-colheita, além da troca e montagem do sistema de irrigação e fertilização. No setor de fruticultura realizamos práticas de poda drástica em cajueiros, poda simples em aceroleiras, retirada de tutores de mamoeiros e a polinização artificial da atemoeira.

$\mathrm{Na}$ área de Física e Biologia do Solo aprendemos a fazer uma Avaliação da Qualidade do Solo, desenvolvida por pesquisadores do IF-Sertão Pernambucano Campus Petrolina Zona Rural, tendo como objetivo fornecer aos agricultores uma tecnologia de baixo custo e alta eficiência que ajude-os a monitorar a qualidade do seu solo.

\section{Imagem 1: Práticas Agroecológicas no Semiárido de Pernambuco}
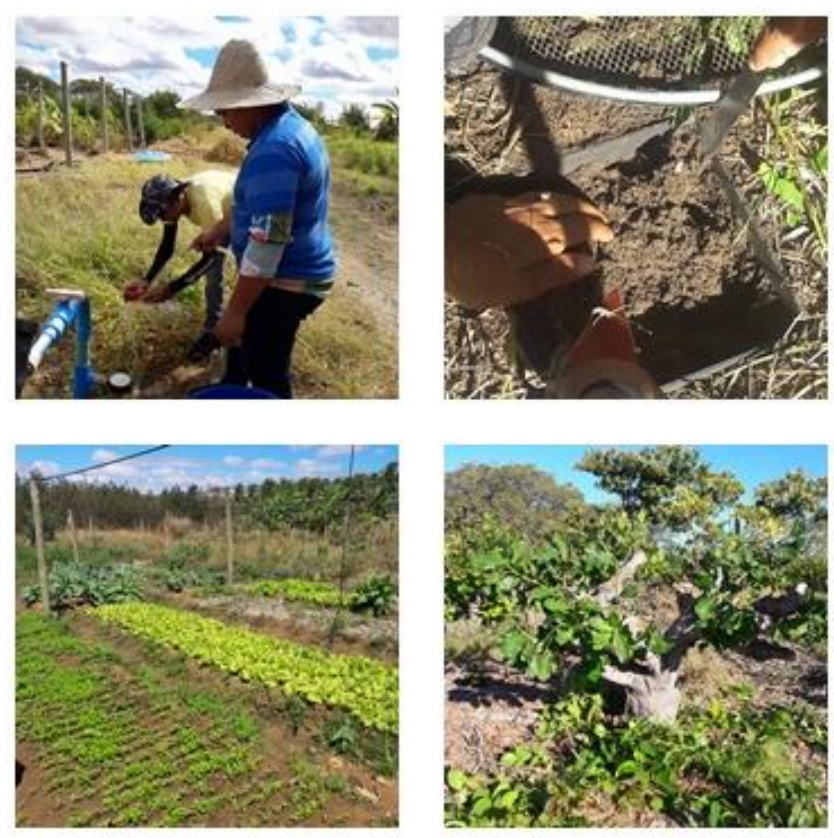

\section{Considerações}

A participação no curso contribuiu para com a formação e o desenvolvimento de saberes e competências na agricultura de base ecológica. Existem diversas tecnologias de convivência com o semiárido que através da adaptabilidade podem ser implantadas na zona da mata, contribuindo para com o processo de segurança alimentar das famílias dos agricultores. Além de serem economicamente viáveis, essas tecnologias são socialmente justas e ecologicamente corretas. 


\section{Referências}

CAPORAL, Francisco Roberto. Agroecologia: alguns conceitos e princípios. Brasília: MDA/SAF/DATER-IICA, 2004. 